\title{
PLURALIDADE DAS ORDENS JURÍDICAS: UMA NOVA PERSPECTIVA NA RELAÇÃO ENTRE O DIREITO INTERNACIONAL E O DIREITO CONSTITUCIONAL
}

\author{
PLURALISM OF LEGAL ORDERS: TOWARD A NEW PERSPECTIVE OF THE RELATIONSHIP \\ BETWEEN INTERNATIONAL AND CONSTITUTIONAL LAW
}

André de Carvalho Ramos*

\begin{abstract}
Resumo:
O presente artigo visa analisar o novo fenômeno da pluralidade das ordens jurídicas, enfocando os aspectos de convergência e divergência entre o Direito Internacional e o Direito Nacional. Por fim, o artigo defende a possibilidade de harmonia entre as ordens jurídicas plurais, com base uma nova perspectiva na relação entre o Direito Internacional e o Direito Interno.
\end{abstract}

Palavras-chave: Direito Internacional. Direito Constitucional. Monismo. Dualismo. Humanos. Transconstitucionalismo. Controle de Convencionalidade. Bloco de Constitucionalidade

\begin{abstract}
:
This article aims to analyse the new phenomena of the legal pluralism treaties in Brazil, focusing on the convergence and divergence of the international law and the constitutional law. At the end, the article sustains the possibility of achieving harmony into the legal pluralism, due to a new perspective of the relationship between international and constitutional law.
\end{abstract}

Keywords: International law. Constitutional Law. Monism. Dualism. Transconstitucionalism. Control of Conventionality. Constitutionality Bloc.

A proposta do artigo: a pluralidade normativa e a relação entre o Direito Internacional e o direito interno.

O Direito Internacional é uma realidade impressionante no Brasil do século XXI. Do ponto de vista da produção normativa, o Brasil aderiu a centenas de tratados nos mais diversos planos (universal, regional) e temas (gerais, setoriais), bem como tem acatado inúmeros diplomas normativos de soft law. A cada ano, novas demandas são traduzidas em textos internacionais e o Brasil é um dos países mais receptivos a essa produção normativa. Do ponto de vista do alcance, a influência do Direito Internacional

\footnotetext{
* Professor Associado da Faculdade de Direito da Universidade de São Paulo (Largo São Francisco), Doutor e Livre-Docente em Direito Internacional, Procurador Regional da República.
} 
atinge todos os temas da conduta social nacional, mostrando uma impressionante força expansiva de suas normas.

Esse inesgotável fôlego normativo associado à sua força expansiva insere o Direito Internacional no epicentro da temática da pluralidade de ordens jurídicas que disputam a regência da vida social no século XXI.

A temática - ordens jurídicas plurais, ${ }^{1}$ - é fruto justamente da expansão do Direito Internacional, com várias ramificações e subsistemas (Direito da Integração, Direito Internacional dos Direitos Humanos, etc.), que ocupa temáticas outrora reservadas ao Direito Nacional.

Essa geografia expansiva do Direito Internacional é digna de nota: nada, hoje, escapa ao furor normativo internacional, que possui normas que abrangem todos os ramos do Direito Interno (Direito Penal, Processual, etc.,).

Porém, essa geografia expansiva não gerou regras claras de convivência entre o Direito Internacional atual e o Direito Interno. Pelo contrário, possuímos ainda um cenário no qual não há claramente um primus inter pares e os desejos de supremacia de todas as ordens jurídicas envolvidas não são abandonados.

Exemplo disso é a relação do Direito Internacional com as Constituições dos Estados. Com efeito, o pilar dos ordenamentos dos Estados de Direito é o princípio da supremacia da Constituição.

Por sua vez, o Direito Internacional adota um unilateralismo internacionalista: não admite que suas normas sejam descumpridas sob a escusa de óbices internos, como se vê da leitura do art. 27 da Convenção de Viena sobre Direito dos Tratados (1969). ${ }^{2}$ Essa supremacia internacionalista é garantida pela interpretação ofertada pelos órgãos internacionais judicias e quase-judiciais. Desde a redemocratização, o Brasil ratificou centenas de tratados e se submeteu à interpretação de vários órgãos internacionais, como, por exemplo, o Tribunal Permanente de Revisão do Mercosul, a Corte Interamericana de Direitos Humanos, o Tribunal Penal Internacional, o Órgão de Solução de Controvérsias da Organização Mundial do Comércio, entre outros.

Consequentemente, o Brasil - por sua livre vontade - possui agora textos normativos de ordens diversas (de matriz constitucional e de matriz internacional) que podem colidir e, para piorar, pode existir interpretação diversa sobre o mesmo diploma (o Supremo Tribunal Federal interpretando as normas internacionais incorporadas internamente de modo dissonante dos órgãos criados pelos próprios tratados). Se não avançarmos na análise do fenômeno da pluralidade das ordens jurídicas surge o risco do choque das placas tectônicas, com danos a todos os ordenamentos envolvidos.

1 DELMAS-MARTY, Mireille. Le pluralisme ordonné. Paris: Seuil, 2004.

2 Já ratificada e incorporada internamente. In verbis: Art. 27. Uma parte não pode invocar as disposições de seu direito interno para justificar o inadimplemento de um tratado. Esta regra não prejudica o art. 46. 
Fica estabelecido o cerne das discussões envolvendo a pluralidade de ordens jurídicas: qual é o modo de convivência entre as normas e decisões de diferentes origens? É possível o diálogo? É possível retroceder a um mundo no qual o Estado é o senhor dos tratados, cabendo-lhe interpretar ao seu gosto suas normas, inclusive ditando a subordinação dos tratados às normas internas? Caminhamos para a mutilação da supremacia da Constituição, que cederia às normas e decisões de órgãos judiciais e quasejudiciais internacionais?

Em resumo, os ordenamentos podem se chocar, tal qual as placas tectônicas, com decisões contraditórias oriundas do plano doméstico e do plano internacional.

No Brasil, o choque das placas tectônicas era questão de tempo e ocorreu, com estardalhaço, em 2010, no julgamento da Arguição de Descumprimento de Preceito Fundamental n. 153 pelo STF e, meses depois, na condenação do Brasil no Caso Gomes Lund perante a Corte Interamericana de Direitos Humanos. Como veremos, o mesmo objeto (lei brasileira de anistia aos agentes da ditadura militar, envolvidos em graves violações de Direitos Humanos), foi apreciado por dois Tribunais vinculados a ordens jurídicas distintas, com decisões aparentemente contraditórias.

Este artigo tem como proposta analisar o fenômeno da pluralidade das ordens normativas focado na situação brasileira e propor as alternativas possíveis.

1. O conceito de pluralidade das ordens jurídicas e as diferentes terminologias

A temática da pluralidade das ordens jurídicas é investigada há muito pela doutrina constitucionalista, com várias denominações, como, por exemplo, constitucionalismo multinível (Pernice, ${ }^{3}$ ao que tudo indica um dos pioneiros), pluralismo constitucional (Walker $\left.{ }^{4}\right)$, interconstitucionalidade (Canotilho ${ }^{5}$ ), transconstitucionalismo $\left(\mathrm{Neves}^{6}\right)$, cross-constitucionalismo (Ramos Tavares ${ }^{7}$ ), constitucionalismo transnacional (Aragón Reyes ${ }^{8}$ ), entre os mais diversos autores estrangeiros e nacionais que trataram sobre o tema recentemente. Essas denominações explicitam a ótica de partida, que é o

3 Ver entre outros, PERNICE, Ingolf. Multilevel constitutionalism and the Treaty of Amsterdam: European constitution-making revisited in 36 Common Market Law Review, 1999, pp.703-750. PERNICE, Ingolf. The Treaty of Lisbon: Multilevel Constitutionalism in Action in The Columbia Journal of European Law, Vol. 15, no. 3 Summer 2009, p. 350-407.

4 WALKER, Neil. The Idea of Constitutional Pluralism in 65 The Modern Law Review, 2002, p. 317 et seq, em especial p. 339.

5 CANOTILHO, José Joaquim Gomes. Brancosos e Interconstitucionalidade. Itinerários dos Discursos sobre a Historicidade Constitucional. Coimbra: Almedina, 2008.

6 NEVES, Marcelo. Transconstitucionalismo. São Paulo: Martins Fontes, 2009.

7 TAVARES, André Ramos. Modelos de uso da jurisprudência constitucional estrangeira pela justiça constitucional. Revista Brasileira de Estudos Constitucionais. Belo Horizonte, ano 3, n.12, pp. 17-55, 2009.

8 ARAGÓN REYES, Manuel La Constitución como paradigma in CARBONELL SÁNCHEZ, Miguel. Teoría del neoconstitucionalismo: ensayos escogidos. Madrid: Trotta, 2007. p. 29-40. 
direito constitucional e demonstram a saudável preocupação dos constitucionalistas com a ascensão do Direito Internacional.

Partindo da ótica mais próxima do Direito Internacional, há aqueles que usam a denominação internacionalização do Direito, que constata a impregnação de normas internacionais em todos os ramos do direito nacional e gera o pluralismo de ordens jurídicas (Delmas-Marty $\left.{ }^{9}\right)$.

Em essência, o pluralismo de ordens jurídicas consiste na coexistência de normas e decisões de diferentes matrizes com ambição de regência do mesmo espaço social, gerando uma série de consequências relacionadas à convergência ou divergência de sentidos entre as normas e decisões de origens distintas. As ordens jurídicas plurais, então, são aquelas que convergem e concorrem na regência jurídica de um mesmo espaço (a sociedade nacional).

Esse fenômeno é fruto de evento antigo e consistente: a expansão quantitativa e qualitativa do Direito Internacional, que convive - como veremos - com o ordenamento nacional, outrora regente quase exclusivo da vida social. Ao mesmo tempo, esse pluralismo advém das mudanças profundas no seio do constitucionalismo contemporâneo, em plena época do chamado neoconstitucionalismo e de abertura do Direito Constitucional ao Direito Internacional.

Surgem, então, influências recíprocas, diálogo e, eventualmente, dissonâncias. Esses eventos associados à pluralidade das ordens jurídicas ganharam visibilidade e importância nossos últimos vintes anos, embora o Direito Internacional esteja em convívio com o Direito Constitucional há séculos. Porém, existem motivos recentes, de matriz internacional e de matriz constitucional, que explicam o crescimento exponencial das consequências associadas à pluralidade das ordens jurídicas nos últimos anos, como veremos a seguir.

2. A constitucionalização do Direito Internacional como impulsionador do fenômeno da pluralidade de ordens jurídicas

O fenômeno da pluralidade das ordens jurídicas ganha importância no final do século XX e início do século XX graças ao fortalecimento do Direito Internacional como meio de regência das condutas humanas.

Presenciamos a juridificação das relações internacionais, fenômeno que consiste na formatação jurídica das relações internacionais outrora dominadas pelas injunções de força. ${ }^{10}$ Para assumir o papel de regulador das tensões internacionais, no

9 DELMAS-MARTY, Mireille. Le pluralisme ordonné. Paris: Seuil, 2004.

10 RAMOS, André de Carvalho. Rule of law e a judicialização do Direito Internacional: da mutação convencional às guerras judiciais. In: BEDIN, Gilmar Antonio. (Org.). Estado de Direito, Jurisdição Universal e Terrorismo. 1. ed. Ijui: Unijui, 2009. v. 1, p. 85-122. 
pós-guerra fria e em plena era da globalização, o Direito Internacional sofreu uma forte expansão quantitativa e, ainda, uma expansão qualitativa.

Por expansão quantitativa eu denomino o aparentemente inesgotável manancial de produção de normas internacionais sobre os mais diversos campos da conduta social. Esse furor normativo criou obrigações invasivas, aptas a reger a conduta das sociedades internas (e não somente a conduta dos Estados no campo diplomático, interestatal), como é o caso das obrigações de Direitos Humanos, de comércio internacional, de regime de benefícios tributários etc.

Já a expansão qualitativa consiste no fortalecimento de procedimentos internacionais de interpretação e cumprimento das normas, superando, em vários subramos do Direito Internacional, a tradicional descentralização e fragilidade na execução das normas internacionais. De acordo com a visão tradicional do Direito Internacional, a sociedade internacional era uma sociedade paritária e descentralizada, na qual o Estado era o produtor, destinatário e intérprete das normas. Assim, o Estado poderia violar as normas internacionais, ao mesmo tempo em que alegava estar cumprindo-as, em um verdadeiro truque de ilusionista. ${ }^{11}$ Isso era possível por ser o Estado o senhor dos tratados, apto a interpretar seu real alcance e sentido. Com esse judex in causa sua, o Estado poderia comprometer-se perante o Direito Internacional, violar repetidamente suas normas, mas protestar - em sua defesa - que estaria cumprindo tais normas sob a sua peculiar ótica.

Contudo, o alargamento normativo no Direito Internacional convenceu os Estados sobre os benefícios para o abandono do truque de ilusionista, pelo qual os Estados descumpriam uma obrigação internacional, mas alegavam que estavam cumprindo-a, de acordo com sua interpretação. Esse alargamento gerou uma crescente complexidade das normas internacionais, com obrigações cada vez mais invasivas e reguladoras das mais diversas facetas da vida social doméstica. Ao aceitar tais obrigações, os Estados - ao mesmo tempo - exigiram um sistema que assegurasse que os demais Estados parceiros não iriam adotar o truque de ilusionista. Assim, a desconfiança entre os Estados fez nascer uma aceitação galopante de sistemas de solução de controvérsias, nos quais se obtém uma interpretação internacionalista das normas.

Em síntese, os Estados, pressionados pelos desafios transfronteiriços da globalização, aceitaram a expansão quantitativa do Direito Internacional, mas exigiram, desconfiados e temendo falsos comprometimentos, que houvesse procedimentos internacionais que assegurassem a correta interpretação e implementação das normas produzidas.

11 RAMOS, André de Carvalho. Responsabilidade Internacional do Estado por Violação de Direitos Humanos. Revista CEJ (Brasília), Brasília, v. 29, 2005, pp. 53-63 
Esses sistemas internacionais de solução de controvérsia servem tanto para garantir a plena efetividade das normas internacionais, quanto para assegurar o seu pleno desenvolvimento por meio de uma intensa atividade de interpretação judicial.

Consequentemente, a expansão quantitativa do Direito Internacional engendrou uma expansão qualitativa, com a criação de inúmeros tribunais internacionais e órgãos quase-judiciais que fornecem uma interpretação imparcial e concretizam o dever de cumprimento das normas internacionais. Há, na atualidade, uma proliferação dos próprios mecanismos de solução de controvérsia, ${ }^{12}$ gerando a constitucionalização do Direito Internacional.

A constitucionalização do Direito Internacional consiste em um fenômeno pelo qual o Direito Internacional mimetiza institutos outrora reservados ao Direito Constitucional, como, v.g., criação de tribunais, proteção de direitos fundamentais, rule of law, acesso direto de indivíduos, julgamento de indivíduos no campo penal (até com pena de caráter perpétuo), entre outros.

Como expõe Rothenburg, em outras palavras, A lógica do constitucionalismo, com a consagração de documentos jurídicos vinculantes, portadores de direitos fundamentais e de instituições e procedimentos estruturais da organização política, garantidos judicialmente por tribunais internacionais, projeta-se numa dimensão supraestatal (constitucionalismo global). ${ }^{13}$

Uma das mais evidentes provas dessa nova fase do Direito Internacional é o crescimento exponencial de tribunais internacionais nos últimos tempos.

Os números são eloquentes. Houve o estabelecimento de doze novos tribunais internacionais nos últimos vinte anos, como o Tribunal do Mar, a Corte do Espaço Econômico Europeu (EFTA Court), a Corte Centro-Americana de Justiça, a Corte da Comunidade de Estados Independentes, a Corte de Justiça do Mercado Comum do Sudeste e Leste Africano (Comesa Court), o Tribunal Penal Internacional, o Tribunal de Justiça da Comunidade Econômica da África Ocidental (Ecowas Court), o Tribunal de Justiça do Mercado Comum do Caribe (Caricom Court) e a Corte Africana de Direitos Humanos e dos Povos. ${ }^{14}$

Ou seja, nesses últimos anos foram criados mais tribunais internacionais permanentes do que em todas as décadas anteriores, pois, até 1990, existiam apenas seis em atividade, a saber, Corte Internacional de Justiça, Tribunal de Justiça das Comunidades

12 ROMANO, Cesare. The proliferation of international judicial bodies: the pieces of the puzzel, in 31 New York University Journal of International Law and Politics (1999), pp. 710-751, em especial pp.728-729.

13 ROTHENBURG, Walter Claudius. Direito Constitucional. São Paulo: Verbatim, 2010, p. 30.

14 Ver mais sobre a explosão do número de tribunais internacionais em RAMOS, André de Carvalho. Direitos Humanos na Integração Econômica. Rio de Janeiro: Renovar, 2008. 
Européias, do Pacto Andino, do Benelux e as Cortes Européia e Interamericana de Direitos Humanos. ${ }^{15}$

A esses novos tribunais, há de se somar um conjunto de soluções arbitrais instituídas no seio da Organização Mundial do Comércio (OMC), no Acordo de LivreComércio da América do Norte (NAFTA) e no próprio Mercosul (Tribunal Permanente de Revisão), que, em paralelo com a Corte Permanente de Arbitragem e o Centro Internacional para Resolução de Disputas Internacionais (ICSID), se constituem em amostra significativa do desenvolvimento de instituições judiciais e arbitrais na cena internacional.

Tudo isso sem mencionar os tribunais internacionais temporários e ad hoc, como os Tribunais internacionais penais para a ex-Iugoslávia e para Ruanda, bem como os tribunais internacionalizados ou híbridos, que são tribunais internos, financiados, organizados e com forte ingerência (inclusive com a nomeação de juízes) da Organização das Nações Unidas, mas contando também com a participação do Estado. ${ }^{16}$

Por outro lado, cresceu também o número de órgãos quase-judiciais especialmente na área da proteção de Direitos Humanos. Tais órgãos, compostos por especialistas independentes, analisam petições contra Estados e determinam a compatibilidade ou não de determinada conduta estatal com seus compromissos internacionais.

Essa expansão do Direito Internacional acelerou-se com as crises vivenciadas pela humanidade nesse amanhecer do século XXI. Há uma crise ambiental, que assola o planeta (o derretimento do Pólo Norte é apenas um de seus exemplos), social (a desigualdade social crônica e miséria de centenas de milhões envergonham a humanidade), econômica (com a crescente debilidade do dólar, moeda nacional internacional, porém sem lastro e dependente cada vez mais dos desejos chineses) e política (com as guerras sem fim, violações brutais de direitos e omissão da ONU). Tais crises erodem a capacidade de um Estado isolado de fazer frente a tais desafios, como se vê hoje na crise econômica dos Estados Unidos e da Europa, o que gera o apelo ao Direito Internacional.

3. O neoconstitucionalismo como impulsionador do fenômeno da pluralidade de ordens jurídicas

No plano interno, o fenômeno da pluralidade de ordens jurídicas foi impulsionado pela nova configuração do Direito Constitucional.

\footnotetext{
15 Ver mais sobre as Cortes Européia e Interamericana de Direitos Humanos em RAMOS, André de Carvalho. Processo Internacional de Direitos Humanos. 2. ed. São Paulo: Saraiva, 2012.

16 RAMOS, André de Carvalho. Processo internacional de direitos humanos. 2. ed. São Paulo: Saraiva, 2012.
} 
Em vários países, cristaliza-se o chamado neoconstitucionalismo, que prega a interpretação da Constituição vinculada aos princípios, defende a irradiação das normas constitucionais para todo o ordenamento (constitucionalização do Direito), sugere ativismo judicial (em especial da jurisdição constitucional) para fazer valer os valores constitucionais e aceita a abertura da Constituição às normas internacionais, para fazer frente aos desafios sociais, econômicos, ambientais e políticos pelos quais passa o Estado. ${ }^{17}$

Essa abertura ao Direito Internacional é muitas vezes fixada claramente no texto constitucional, como se vê nas Constituições de Portugal de 1976 (art. 16.2 $2^{18}$ ), da Espanha de 1978 (art. 10.2 ${ }^{19}$ ), da África do Sul de 1996 (art. 39.1, c co ) e, em especial, na do Brasil de 1988 (art. $5^{\circ}$, parágrafos $2^{\circ}$ e $3^{\circ}$ ).

Fica claro que as Constituições e a doutrina constitucionalista não ficaram imunes ao furor normativo do Direito Internacional e ao desejo, cada vez maior, dos Estados de aceitarem normas internacionais invasivas e órgãos judiciais internacionais para ditar a interpretação internacionalista dos tratados.

Resta saber se essa abertura constitucionalista ao Direito Internacional sobreviverá ao reconhecimento de dissonâncias, em especial quanto determinada decisão nacional (v.g, do nosso Supremo Tribuno Tribunal Federal) de interpretação de um tratado for considerada violação deste por um órgão internacional.

17 Para Sarmento o neoconstitucionalismo busca (a) reconhecimento da força normativa dos princípios jurídicos e valorização da sua importância no processo de aplicação do Direito; (b) rejeição ao formalismo e recurso mais freqüente a métodos ou estilos mais abertos de raciocínio jurídico: ponderação, tópica, teorias da argumentação etc.; (c) constitucionalização do Direito, com a irradiação das normas e valores constitucionais, sobretudo os relacionados aos direitos fundamentais, para todos os ramos do ordenamento; (d) reaproximação entre o Direito e a Moral, com a penetração cada vez maior da Filosofia nos debates jurídicos; e (e) judicialização da política e das relações sociais, com um significativo deslocamento de poder da esfera do Legislativo e do Executivo para o Poder Judiciário. SARMENTO, Daniel. Oneoconstitucionalismo no Brasil: riscos e possibilidades. In: LEITE, George Salomão; SARLET, Ingo Wolfgang. (Org.). Direitos fundamentais e estado constitucional: estudos em homenagem a J.J. Gomes Canotilho. São Paulo: Editora Revista dos Tribunais; Coimbra: Coimbra Editora, 2009. p. 9-49, em especial p. 9.

18 Art. 16. ${ }^{\circ}$ Âmbito e sentido dos direitos fundamentais. 1. Os direitos fundamentais consagrados na Constituição não excluem quaisquer outros constantes das leis e das regras aplicáveis de Direito Internacional. 2. Os preceitos constitucionais e legais relativos aos direitos fundamentais devem ser interpretados e integrados de harmonia com a Declaração Universal dos Direitos do Homem.

19 Art. 10. 2. Las normas relativas a los derechos fundamentales y a las libertades que la Constitución reconoce se interpretarán de conformidad con la Declaración Universal de Derechos Humanos y los Tratados y acuerdos internacionales sobre las mismas materias ratificados por España.

20 39. Interpretation of Bill of Rights. When interpreting the Bill of Rights, a court, tribunal or forum must promote the values that underlie an open and democratic society based on human dignity, equality and freedom; must consider international law; and may consider foreign law. When interpreting any legislation, and when developing the common law or customary law, every court, tribunal or forum must promote the spirit, purport and objects of the Bill of Rights. The Bill of Rights does not deny the existence of any other rights or freedoms that are recognised or conferred by common law, customary law or legislation, to the extent that they are consistent with the Bill. 
4. Harmonia e Dissonância: os efeitos da pluralidade de ordens jurídicas

Somados esses motivos de matrizes internacional e constitucional, fica claro o quadro do pluralismo de ordens jurídicas no Brasil de hoje: de um lado, temos as normas e intérpretes internacionais; de outro, há as normas internas e seus intérpretes tradicionais, como os juízes e Supremas Cortes.

Ocorre que essas normais internacionais e nacionais reúnem-se no âmbito do Estado Nacional, gerando uma série de fenômenos que refletem harmonia e dissonância. ${ }^{21}$

\subsection{Harmonia}

No campo da harmonia, podemos listar os seguintes fenômenos: a) a abertura do ordenamento interno às fontes internacionais (convencionais ou extraconvencionais); b) reconhecimento de um estatuto superior das normas internacionais ou das decisões internacionais, com a consagração do bloco de constitucionalidade composto por normas internacionais agora com hierarquia constitucional; c) uso retórico e argumentativo da ratio decidendi internacional para fundamentar a decisão nacional, incrementando seu poder de convencimento, especialmente útil nas rupturas hermenêuticas promovidas pelos Tribunais nacionais; d) influência dos avanços nacionais na redação e interpretação do Direito Internacional, especialmente vista na interpretação de Direitos Humanos nos órgãos internacionais, sempre abertos a novos marcos de proteção (mesmo de origem nacional).

Usaremos o exemplo brasileiro para esclarecer esses fenômenos de harmonia ocasionados pela existência das ordens jurídicas plurais.

\subsubsection{A abertura do ordenamento interno pelas fontes internacionais}

A Constituição exigiu um procedimento complexo que deve reunir a vontade concordante dos Poderes Executivo e do Legislativo para que um tratado internacional possa ser incorporado ao ordenamento jurídico nacional. As bases constitucionais são o art. 84, VIII, que estabelece que compete ao Presidente da República celebrar tratados, convenções e atos internacionais, sujeitos a referendo do Congresso Nacional e, ainda, o art. 49, I que dispõe que é da competência exclusiva do Congresso Nacional resolver definitivamente sobre tratados, acordos ou atos internacionais que acarretem encargos ou compromissos gravosos ao patrimônio nacional.

A participação dos dois Poderes na formação da vontade brasileira em celebrar definitivamente um tratado internacional consagrou a chamada teoria da junção

$21 \quad$ NEUMAN, Gerald L. Human rights and constitutional rights: harmony and dissonance, 55 Stanford Law Review, p. 1863-1900, 2003. 
de vontades ou teoria dos atos complexos: para que um tratado internacional seja formado é necessária a conjunção de vontades do Poder Executivo e do Poder Legislativo.

A primeira etapa do iter é composta pelas negociações e assinatura dos tratados internacionais. Essa etapa cabe ao Chefe de Estado (ou seus prepostos), por decorrência implícita do disposto no art. 84, VIII, que dispõe que compete ao Presidente da República celebrar tratados, convenções e acordos internacionais, sujeitos a referendo do Congresso Nacional. A segunda etapa do iter de formação dos tratados no Brasil é a da aprovação congressual ou fase do decreto legislativo. $\mathrm{O}$ trâmite da aprovação congressual é o seguinte: o Presidente encaminha mensagem presidencial ao Congresso Nacional, fundamentada (a exposição de motivos é feita pelo Ministro das Relações Exteriores), solicitando a aprovação congressual ao texto do futuro tratado, que vai anexado na versão oficial em português. Nasce, então, um projeto de decreto legislativo. Caso haja aprovação, o Presidente do Senado promulga e publica o decreto legislativo com o texto do tratado. Com isso, fica o Presidente da República autorizado a celebrar em definitivo do tratado por meio da ratificação ou ato similar. Temos, após a ratificação, o fim do ciclo de formação de um tratado para o Brasil. Porém, a norma, válida internacionalmente, não será válida internamente até que seja editado o Decreto de Promulgação (também chamado de Decreto Executivo ou Decreto Presidencial) pelo Presidente da República e referendado pelo Ministro das Relações Exteriores (art. 87, I da Constituição). Esse Decreto inova a ordem jurídica brasileira, tornando válido o tratado no plano interno.

Além dessa abertura da Constituição aos tratados internacionais, há ainda fontes extraconvencionais, como o costume internacional, que têm sido diuturnamente aplicadas no ordenamento brasileiro. Contudo, há omissão da Constituição brasileira, que, ao tratar do Direito Internacional, restringiu-se a poucos artigos que envolvem tratados (fontes convencionais). Essa omissão não impediu, contudo, que o Supremo Tribunal Federal (entre outros Tribunais brasileiros) aplicasse diretamente o costume internacional aos processos internos, como se fosse law of the land.

Um dos casos paradigmáticos é o conflito judicial entre a Síria e o Egito (logo após a dissolução da República Árabe Unida), referente à propriedade de imóvel no Rio de Janeiro, que antes da transferência da Capital para Brasília, sediava a antiga embaixada comum. Para o Supremo Tribunal Federal, o costume internacional da imunidade absoluta de jurisdição deveria ser aplicado (par in parem non habet imperium), mesmo contrariando o preceito da Lei de Introdução ao Código Civil (art. 12, §único) e ainda o disposto no art. 89, I do CPC, que estabeleciam ser o juízo brasileiro o único competente para conhecer de ações reais sobre imóveis situados no Brasil. ${ }^{22}$

22 Supremo Tribunal Federal, Ação Civil Originária n. 298-DF, Rel. para o Acórdão Min. Décio Miranda, julgamento em 14.04.1982, publicada no DJ de 17-12-1982. 
No caso da proteção internacional de Direitos Humanos, há também vários exemplos de invocação de normas extraconvencionais de Direitos Humanos como se vê na Adin 3.741, Rel. Min. Ricardo Lewandowski (mencionando a Declaração Universal de Direitos do Homem); HC 81.158-2, Relatora Ministra Ellen Gracie (citando a Declaração Universal dos Direitos da Criança - 1959); HC 82.424-RS, Relator para o Acórdão Min. Maurício Corrêa (forte menção à Declaração Universal dos Direitos Humanos); RE 86.297, Relator Thompson Flores (menção à Declaração Universal dos Direitos do Homem);Adin 3.510, Relator Min. Carlos Britto (no voto do Min. Ricardo Lewandoswki, menção à Declaração Universal sobre Bioética).

Na HC 91.952, o Min. Carlos Britto invocou a Resolução de Prevenção ao Crime e Justiça Penal da ONU (resolução não vinculante da Assembléia Geral), para conforto, no mínimo, intelectual de todos. O Min. Peluso, em seu voto, salientou ter sido indicado Presidente de Comissão da ONU para reforma da sua resolução sobre regras mínimas para tratamento de preso e ainda ter o art. $5^{\circ}$, III reproduzido o art. V da Declaração Universal dos Direitos Humanos. ${ }^{23} \mathrm{Na}$ Adin 1.969, o Min. Relator Lewandoswki invocou, em apoio à sua tese, $\mathrm{o}$ art. XX da Declaração Universal de Direitos Humanos, que trata da liberdade de manifestação. ${ }^{24}$

Chega-se ao ponto de existir exemplos de invocação, como vinculantes, de diplomas internacionais da soft law, ${ }^{25}$ que, em tese, não vinculariam o Brasil. O Min. Ricardo Lewandoswki na Ação Direta de Inconstitucionalidade 3.510-0 decidiu que a Declaração Universal sobre Bioética e Direitos Humanos da UNESCO, diploma não vinculante de acordo com o tratado institutivo da UNESCO, deveria ser respeitada, uma vez que o Brasil, pois, como membro da Organização das Nações Unidas para a Educação, Ciência e Cultura e signatário da Declaração elaborada sob seus auspícios, está obrigado a dar concreção a seus preceitos no âmbito dos três poderes que integram sua estrutura estatal, sob pena de negar consequência jurídica à manifestação de vontade, formal e solene, que exteriorizou no âmbito internacional. ${ }^{26}$

23 Supremo Tribunal Federal, HC 91.952 / SP - São Paulo, Relator: Min. Marco Aurélio, julgamento em 07/08/2008. Órgão Julgador: Tribunal Pleno

24 Supremo Tribunal Federal, ADI 1.969 / DF. Relator: Min. Ricardo Lewandowski, julgamento em 28/06/2007. Órgão Julgador: Tribunal Pleno

25 Para maior detalhe sobre a soft law e os Direitos Humanos, ver RAMOS, André Carvalho. Direitos humanos na integração econômica. Rio de Janeiro: Ed. Renovar, 2008. p. 101-102.

26 Continua o Ministro salientando que: Em outras palavras, a produção legislativa, a atividade administrativa e a prestação jurisdicional no campo da genética e da biotecnologia em nosso País devem amoldar-se aos princípios e regras estabelecidas naquele texto jurídico internacional, sobretudo quanto ao respeito à dignidade da pessoa humana e aos direitos e garantias fundamentais, valores, de resto, acolhidos com prodigalidade pela Constituição de 1988. Disponível em http://www.stf.jus.br/arquivo/cms/noticiaNoticiaStf/anexo/ adi3510RL.pdf. acesso em 28 de janeiro de 2010. 
4.1.2. Reconhecimento do bloco de constitucionalidade composto por normas internacionais agora com hierarquia constitucional

O bloco de constitucionalidade consiste na reunião dos textos considerados de estatura constitucional, o que inclui a Constituição e outros diplomas normativos igualmente considerados de hierarquia constitucional.

No Direito Comparado, o marco do reconhecimento da existência do bloco de constitucionalidade foi a decisão n 71-44 DC, de 16.07.71 do Conselho Constitucional francês, relativa à liberdade de associação, que consagrou o valor constitucional do preâmbulo da Constituição francesa de 1958, que, por sua vez, faz remissão ao preâmbulo da Constituição de 1946 e à Declaração de Direitos do Homem e do Cidadão de 1789. Em 2005, houve alteração do preâmbulo da Constituição francesa e foi agregada remissão à Carta do Meio Ambiente (Charte de l'environment), todos agora fazendo parte do bloco de constitucionalidade.

No Brasil, no Supremo Tribunal Federal em 2002, Celso de Mello, nos limites da discussão do caso, constatou a existência do debate sobre o bloco de constitucionalidade, que amplia o parâmetro de controle de constitucionalidade, devendo abarcar os dispositivos do bloco como paradigma de confronto das leis e atos normativos infraconstitucionais. ${ }^{27}$

No texto constitucional, o art. $5^{\circ}, \S 2^{\circ}$ permite, ao dispor sobre os direitos decorrentes do regime, princípios e tratados de Direitos Humanos, o reconhecimento de um bloco de constitucionalidade amplo, que alberga os direitos previstos nos tratados internacionais de Direitos Humanos. Contudo, até a edição da EC 45/04, o estatuto desses tratados, na visão do $\mathrm{STF}$, era equivalente à mera lei ordinária. A Emenda Constitucional $45 / 2004$ introduziu o $\S 3^{\circ}$ do art. $5^{\circ}$, com a seguinte redação: Art. $5^{\circ}, \S 3^{\circ}$. Os tratados e convenções internacionais sobre Direitos Humanos que forem aprovados, em cada Casa do Congresso Nacional, em dois turnos, por três quintos dos votos dos respectivos membros, serão equivalentes às emendas constitucionais. Com a introdução do art. $5^{\circ}, \S 3^{\circ}$, o STF modificou sua posição, mas ainda situou os tratados aprovados sem o rito especial do citado parágrafo no patamar da supralegalidade. Restam, então, os tratados aprovados pelo rito especial do art. $5^{\circ}, \S 3^{\circ}$, como parte integrante de um bloco de constitucionalidade restrito.

Logo, todos os demais artigos da Constituição que tratam do princípio da supremacia da norma constitucional, como, por exemplo, os referentes ao controle difuso e concentrado de constitucionalidade (art. 102 e 103) devem agora ser lidos como sendo componentes do mecanismo de preservação da supremacia do bloco de constitucionalidade como um todo e não somente da Constituição.

27 ADI 595 / ES, decisão monocrática do Relator Min. Celso de Mello, julgamento: 18/02/2002. No mesmo sentido, ver a decisão monocrática na ADI 514 / PI, Relator Celso de Mello, Julgamento: 24/03/2008. 
Assim, várias são as conseqüências. Em primeiro lugar, a constitucionalização do Direito, fenômeno pelo qual todas as normas do ordenamento sofrem influência dos comandos constitucionais, é agora regida pelas normas da Constituição e ainda pelas normas dos tratados celebrados sob o rito especial. A filtragem constitucional do ordenamento, ou seja, a exigência de coerência de todo o ordenamento aos valores da Constituição passa contar também com o filtro dos valores existentes nesses tratados de rito especial.

Consequentemente, as normas paramétricas de confronto no controle de constitucionalidade devem levar em consideração não só a Constituição, mas ainda os tratados celebrados pelo rito especial. Portanto, cabe acionar o controle abstrato de constitucionalidade, em todas as suas modalidades, para fazer valer as normas previstas nesses tratados. Por exemplo, cabe arguição de descumprimento de preceito fundamental quer de preceito fundamental previsto na Constituição ou nesses tratados. Em terceiro lugar, cabe recurso extraordinário quando a decisão impugnada contrariar dispositivo da Constituição ou dos tratados celebrados sob o rito especial.

Os primeiros tratados que foram aprovados de acordo com esse rito foram a Convenção das Nações Unidas sobre os Direitos das Pessoas com Deficiência e seu Protocolo Facultativo, assinados em Nova Iorque, em 30 de março de 2007. Além de robusto rol de direitos previsto na Convenção, cabe ressaltar a submissão brasileira ao sistema de petição das vítimas de violação de direitos previstos ao Comitê sobre os Direitos das Pessoas com Deficiência, de acordo com o Protocolo Facultativo.

\subsubsection{Uso retórico e argumentativo da ratio decidendi internacional para fundamentar a decisão nacional}

Outro exemplo de harmonia entre as ordens internacional e nacional é o uso retórico e argumentativo da ratio decidendi internacional para fundamentar a decisão nacional, incrementando seu poder de convencimento, especialmente útil nas rupturas hermenêuticas promovidas pelos Tribunais nacionais.

Como exemplo, podemos citar o caso da obrigatoriedade do diploma de jornalista para o exercício da profissão de jornalismo. A obrigatoriedade estava prevista no Decreto-Lei n. 972/69 e foi derrubada por ação civil pública promovida pelo Ministério Público Federal no Estado de São Paulo, ${ }^{28}$ em julgamento final em 2009 (depois de quarenta anos de obrigatoriedade) perante o Supremo Tribunal Federal (R.E 511.96129). Para o STF, a obrigatoriedade do diploma era incompatível com as liberdades de profissão, de expressão e de informação previstas nos art. 5, IX e XIII, e 220, da CF, bem como

28 O autor do presente artigo, na época Procurador Regional dos Direitos do Cidadão, foi o proponente da ação civil pública em questão.

29 BRASIL. Supremo Tribunal Federal. RE 511.961-SP, Recorrente: Ministério Público Federal e outro, Recorridos: União e outro. Rel. Min. Gilmar Mendes, julgamento em 17.6.2009. 
violava o disposto no art. 13 da Convenção Americana de Direitos Humanos, tal qual interpretado pela Corte Interamericana de Direitos Humanos. O voto do Min. Gilmar Mendes (relator) citou longamente a Opinião Consultiva n. 5 da Corte Interamericana de Direitos Humanos, que, ao interpretar a Convenção Americana de Direitos Humanos, repudiou severamente essa obrigatoriedade. Assim, 40 anos de obrigatoriedade do diploma de jornalismo foram descartados pelo STF, com forte apoio na jurisprudência internacional de Direitos Humanos.

4.1.4. Uso das leis e decisões nacionais para influenciar a redação e interpretação do Direito Internacional

Outro exemplo de harmonia é o uso de leis e decisões nacionais para influenciar a redação e interpretação do Direito Internacional, especialmente na interpretação de Direitos Humanos nos órgãos internacionais, sempre abertos a novos marcos de proteção (mesmo de origem nacional).

Um exemplo, narrado em meu livro sobre a Teoria Geral dos Direitos Humanos na Ordem Internacional, é o caso Goodwin perante a Corte Europeia de Direitos Humanos. No caso, Christine Goodwin, depois de submeter-se a cirurgia de modificação de sexo (masculino de origem para feminino), acusou o Reino Unido de violação do direito à vida privada previsto no art. $8^{\circ}$ da Convenção Européia de Direitos Humanos. A vítima alegou que não pode se inscrever na Seguridade Social com o novo sexo, nem se beneficiar com a idade reduzida de aposentadoria para mulheres ou ainda com os prêmios de seguros mais baratos para mulheres e tampouco pode invocar a proteção penal contra estupro (que exigiria segundo a interpretação local o sexo original feminino), e finalmente, não pode se casar com seu companheiro homem (art. 12 da Convenção - direito ao matrimônio). A Corte condenou, em julgamento de julho de 2002, o Reino Unido por violação do art. 8 (direito à vida privada) e também do art. 12 (direito ao matrimônio). As novas legislações da Holanda, Itália e Turquia, reconhecendo direitos aos transexuais, foram importantes fatores para o convencimento da Corte. Além disso, a Corte ponderou que, em pleno século XXI (a decisão é de 2002) e com os avanços da ciência, era incoerente reconhecer, em termos médicos, a possibilidade de cirurgia e tratamento psicológico e hormonal de mudança de sexo e não reconhecer os efeitos jurídicos de tal mudança. ${ }^{30}$

30 RAMOS, André de Carvalho. Teoria geral dos direitos humanos na ordem internacional. 2. ed. São Paulo: Saraiva, 2012. 


\subsection{Dissonância}

\subsubsection{Os tratados internacionais nacionais: uma criação brasileira}

A primeira modalidade de dissonância entre as ordens jurídicas internacional e nacional é o uso doméstico deturpado de tratados e demais normas internacionais graças ao hábito da interpretação nacional de tratados, sem conexão com a interpretação internacional.

No Brasil, essa modalidade fez surgir uma nova espécie de norma: os tratados internacionais nacionais. O modo de criação dessa espécie tipicamente brasileira é o seguinte: o Brasil ratifica tratados e reconhece a jurisdição de órgãos internacionais encarregados de interpretá-los; porém, subsequentemente, o Judiciário nacional continua a interpretar tais tratados nacionalmente, sem qualquer remissão ou lembrança da jurisprudência dos órgãos internacionais que os interpretam.

Porém, o reconhecimento da interpretação internacional dos tratados ratificados pelo Brasil é consequência óbvia dos vários comandos constitucionais que tratam de tratados. De que adiantaria a Constituição pregar o respeito a tratados internacionais se o Brasil continuasse a interpretar os comandos neles contidos nacionalmente?

Essa consequência natural da aceitação de tratados pelos diversos Estados foi detectada pela Suprema Corte de Justiça da Argentina no emblemático julgamento de 2005 sobre as leis de punto final e obediencia debida, que assim se pronunciou: "De nada serviría la referencia a los tratados hecha por la Constitución si su aplicación se viera frustrada o modificada por interpretaciones basadas en uno u otro derecho nacional". ${ }^{31}$

Contudo, há pouca discussão sobre a consequência natural da ratificação de tratados internacionais pelo Brasil, que é a adoção dos parâmetros internacionais de interpretação dessas normas. Verifico, então, que o Direito Internacional no Brasil está manco: formalmente, o Brasil está plenamente engajado; na aplicação prática, há quase um total silêncio sobre a interpretação dada pelo próprio Direito Internacional (na voz de seus intérpretes autênticos, como, por exemplo, a Corte Interamericana de Direitos Humanos, o Tribunal Permanente de Revisão do Mercosul, etc.).

Se a interpretação judicial brasileira for contrária à interpretação desses órgãos internacionais, o Brasil responderá por isso e, pior, para o jurisdicionado existirá a sensação de que o tratado em tela foi distorcido e só foi usado como retórica judicial para fins de propaganda externa.

31 Sentencia de la Suprema Corte de Justicia de la República de Argentina, S. 1767. XXXVIII, Causa n. 17.768, 14 de junho de 2005, parágrafo 14. 
4.2.2. A decisão judicial interna que invalida tratados internacionais sem qualquer modulação temporal

Há vários casos de declaração de inconstitucionalidade pelo Supremo Tribunal Federal de tratados incorporados internamente. Para citar apenas um precedente, decidiu o STF que: Supremacia da CF sobre todos os tratados internacionais. O exercício do treaty-making power, pelo Estado brasileiro, está sujeito à observância das limitações jurídicas emergentes do texto constitucional. Os tratados celebrados pelo Brasil estão subordinados à autoridade normativa da CF. Nenhum valor jurídico terá o tratado internacional, que, incorporado ao sistema de direito positivo interno, transgredir, formal ou materialmente, o texto da Carta Política. Precedentes..$^{32}$

Só que essa declaração de inconstitucionalidade não afeta a validade internacional dos tratados. Ficamos expostos, então, a responsabilização internacional por descumprimento de um tratado. É imprescindível, caso imperiosa a constatação da inconstitucionalidade, a aplicação do instituto da modulação de efeitos da declaração de inconstitucionalidade, de uso jurisprudencial consolidado e previsto na Lei n. 9.868/99 (art. 27).

Assim, ao declarar a inconstitucionalidade do tratado internacional incorporado, e tendo em vista o interesse social em não expor o Brasil à sua responsabilização internacional, o Supremo Tribunal Federal, por maioria de dois terços de seus membros, deve limitar os efeitos daquela declaração para determinar que só tenha eficácia a partir da denúncia ou extinção por qualquer meio do tratado, podendo, em nome da segurança jurídica, ser fixado prazo máximo para a ação do Chefe de Estado.

Essa modulação deve abarcar o chamado prazo de pré-aviso, comum em vários tratados, pelo qual a denúncia unilateral só produzirá a extinção das obrigações do Estado denunciante após o decurso de lapso temporal no qual os demais parceiros se adaptam à nova situação (p.ex, o Tratado de Assunção, marco do Mercado Comum do Sul, estabelece o prazo máximo de 2 anos - art. 22).

Esse instituto é essencial para sincronizar a validade interna e internacional dos tratados e pode ser utilizado em qualquer uma das espécies de controle de constitucionalidade.

Caso não seja invocada a modulação, teremos mais um caso de dissonância entre as ordens internacional e nacional.

32 Supremo Tribunal Federal, MI 772-AgR, Rel. Min. Celso de Mello, julgamento em 24-10-2007, Plenário, DJE de 20-3-2009. 
4.2.3. O descumprimento por ordem judicial nacional de decisões internacionais

O último exemplo de dissonância entre as ordens internacional e nacional diz respeito ao caso de ordem judicial nacional para descumprir decisões internacionais. Essa hipótese é fruto do vício nacional de criar os tratados internacionais nacionais e pode ser particularmente desastroso no tocante à resolução vinculante do Conselho de Segurança da ONU ou sentença definitiva da Corte Interamericana de Direitos Humanos.

Ficaremos, de novo, expostos a sanções internacionais, pela incapacidade de criarmos mecanismos de conciliação nesse mundo de pluralidade de ordens normativas.

5. As assimetrias no mundo plural: a ordem internacional como ordem de maior amplitude

A harmonia e a dissonância são produtos claros da pluralidade de ordens jurídicas (Direito Interno e Direito Internacional - nos seus mais diversos sub-ramos), que convergem e concorrem na regência jurídica de um mesmo espaço (a sociedade nacional).

De todos os exemplos de harmonia e dissonância vistos acima, ficou evidenciado um gigantismo do impacto internacional sobre o Direito Interno com pouca influência no sentido inverso.

Ocorre que o maior impacto do direito nacional sobre o Direito Internacional ocorre em momento pré-normativo: os Estados Nacionais são os sujeitos primários do Direito Internacional, atuando decisivamente na redação das normas internacionais. Após a formação das normas internacionais e criação dos tribunais internacionais, o Direito Internacional passa a irradiar sua influência ao direito nacional e expor sua regência da vida social interna. Por isso, a melhor percepção do desenho da pluralidade de ordens jurídicas não é o de uma relação horizontal clássica, com influência recíproca e interdependência. Ao contrário, há círculos concêntricos, com a ordem de maior amplitude (Direito Internacional) sendo formada pelos Estados para irradiar normas e decisões para as ordens de menor amplitude (Direito Nacional).

A ordem de menor amplitude é o círculo menor, que, por definição é nuclear. Como gera o círculo de maior amplitude, pode inclusive renegá-lo. Assim, em última análise, a resposta das ordens de menor amplitude, insatisfeitas, é impor uma reconfiguração (renegociação de tratados, mudanças do costume internacional) ou até a supressão do desenho do círculo de maior amplitude (denúncia do tratado).

Só que as crises mundiais já expostas não favorecem essa solução de ruptura.

Consequentemente, surge uma primeira possibilidade de estímulo da convergência das ordens plurais, que denomino Diálogo das Cortes, a seguir estudado. 
6. O Diálogo das Cortes e seus parâmetros

Com avanços e recuos, vários países do mundo abrem-se ao Direito Internacional, como se vê na União Europeia, no Mercosul, entre outros. No caso brasileiro, é perceptível a explosão normativa internacional, em especial na área dos Direitos Humanos. Inclusive já incorporamos internamente dois tratados de Direitos Humanos seguindo o rito especial do art. 5, parágrafo terceiro (Convenção das Nações Unidas sobre Direitos das Pessoas com Deficiência e seu Protocolo Facultativo).

Nasce a possibilidade de 1) colisão entre textos normativos de origens diversas; 2) colisão entre decisões de órgãos nacionais e internacionais. Como mencionado acima, é possível o choque de placas tectônicas nesse mundo de ordens plurais.

Antes de analisarmos como superamos essas contradições, cabe avaliar se, no atual momento, há consequências positivas do choque de placas tectônicas. De fato, a existência de incoerências e contradições entre normas e decisões pode ser um catalisador para a evolução hermenêutica (progress through catastrophe ${ }^{33}$ ).

Por outro lado, Kumm sustenta que não faz sentido, em um marco normativo plural, buscar um árbitro final qualquer. Assim, o eventual aprimoramento da interpretação normativa compensa incoerências pontuais entre a jurisprudência dos órgãos judiciais em situação de conflito. ${ }^{34}$

Nessa linha, há benefícios advindos da existência de uma pluralidade de ordens jurídicas, pois a comparação recíproca e o diálogo interinstitucional gerado promovem a emergência de interpretações jurídicas extraídas de profunda reflexão. Dupuy sustenta, nesse sentido, que há refinamento na interpretação normativa. ${ }^{35}$

Tal processo que denomino de fertilização cruzada, ${ }^{36}$ é de suma importância para alguns ramos do Direito Internacional, como o Direito Internacional dos Direitos Humanos, que lida com normas de redação genérica, contendo valores muitas vezes conflitantes. Logo, as decisões anteriores sobre o alcance e sentido de determinado direito servem de importante orientação para a formação da jurisprudência de outro tribunal.

33 Expressão de Shany utilizada em RAMOS, André de Carvalho. Direitos humanos na integração econômica. Rio de Janeiro: Renovar, 2008. p. 458.

34 KUMM, Mattias. Who is the final arbiter of constitucionality in Europe? Three conceptions of the relationship between the German Federal Constitucional Court and the European Court of Justice, 36 Common Market Law Review (1999), pp. 351-386, em especial p. 385.

35 DUPUY, Pierre-Marie. The danger of fragmentation or unification of the international legal system and the International Court of Justice in 31 New York University Journal of International Law and Politics (1999), pp.791-807, em especial p.795.

36 Com base nos estudos de Shany, Jacobs e outros. Ver SHANY, Yuval. The competing jurisdictions of International Courts and Tribunals. Oxford: Oxford University Press, 2003, p. 109. JACOBS, Francis G. Judicial Dialogues and Cross-Fertilization of Legal Systems: the European Court of Justice in 38 Texas International Law Journal (2003). p. 547-566. 
O momento atual das ordens jurídicas justapostas é o estágio do Diálogo entre as Cortes: com a fertilização cruzada e uso interconectado de fundamentos, podemos conseguir a harmonia entre as ordens internacional e nacional. ${ }^{37}$ Contudo, não basta reconhecer a pluralidade das ordens jurídicas e pugnar pela harmonia e diálogo sem avançar na discussão do modo pelo qual esse diálogo deve ser travado, com estabelecimento de parâmetros que devem servir para sindicar se, em determinado caso, houve - ou não - o diálogo.

Sem esses parâmetros podemos cair no risco de que essa técnica seja mero instrumento de retórica doutrinária, sem maior relevo na crítica das decisões judiciais.

Pelo contrário, no meu ponto de vista, parametrizar a harmonia e diálogo entre as ordens internacional e nacional serve para desnudar as efetivas opções dos julgadores nacionais, às vezes distintas das veiculadas em discursos para a mídia e para o público em geral.

Nesse sentido, sugerimos os seguintes parâmetros: 1) menção à existência de dispositivos internacionais convencionais ou extraconvencionais vinculantes ao Brasil sobre o tema; 2) menção à existência de caso internacional contra o Brasil sobre o objeto da lide e as consequências disso reconhecidas pelo Tribunal nacional; 3) menção à existência de jurisprudência anterior sobre o objeto da lide de órgãos internacionais aptos a emitir decisões vinculantes ao Brasil; 4) peso dado aos dispositivos e à jurisprudência internacionais.

Caso a decisão nacional tenha preenchido os quatro parâmetros, houve efetivamente um Diálogo das Cortes.

O primeiro parâmetro é descritivo e exige transparência. O órgão judicial nacional reconhece a incidência de normas internacionais ao caso, fazendo nascer o debate sobre a interpretação dos mesmos.

$\mathrm{O}$ segundo parâmetro é referente à coerência e harmonia. O Estado adere a tribunais internacionais e isso exige dos órgãos nacionais ao menos o reconhecimento do trâmite de casos perante o sistema internacional.

O terceiro parâmetro é um atestado da pluralidade normativa dos dias de hoje, concretizando a fertilização cruzada vista acima.

Finalmente, o quarto parâmetro dá publicidade à sociedade brasileira do conteúdo da jurisprudência internacional, óbvia consequência da internacionalização da temática envolvida no caso concreto. Esse parâmetro exige dos julgadores nacionais um esforço argumentativo para convencer a sociedade dos motivos pelos quais o Tribunal nacional contrariou, eventualmente, a interpretação internacional sobre o caso.

37 RAMOS, André de Carvalho. O Diálogo das Cortes: O Supremo Tribunal Federal e a Corte Interamericana de Direitos Humanos. In: AMARAL JUNIOR, Alberto do e JUBILUT, Liliana Lyra (Org.). O STF e o direito internacional dos direitos humanos. São Paulo: Quartier Latin, 2009. p. 805-850. 
No caso do Diálogo das Cortes inexistir ou ser insuficiente para obtermos a convergência das ordens jurídicas plurais, é necessário que se investigue uma alternativa para a preservação da harmonia entre as ordens jurídicas justapostas, como se segue abaixo.

4. A teoria do duplo controle: a convivência entre o controle de constitucionalidade e o controle de convencionalidade

O Estado brasileiro reconheceu a jurisdição, após a redemocratização, de vários mecanismos judiciais ou quase-judiciais internacionais nas suas mais diversas áreas. Corte Interamericana de Direitos Humanos, Tribunal Penal Internacional, Comitês diversos de tratados internacionais de Direitos Humanos, Órgão de Solução de Controvérsias da Organização Mundial do Comércio, Tribunal Permanente de Revisão do Mercosul, são alguns exemplos de como o Brasil avançou no trato do Direito Internacional.

A existência desses órgãos internacionais é de extrema valia para eliminarmos o que já chamei acima de truque de ilusionista dos Estados no plano internacional: ${ }^{38}$ eles assumem obrigações internacionais, as descumprem com desfaçatez, mas alegam que as estão cumprindo, de acordo com sua própria interpretação.

O judex in causa sua típico do Direito Internacional - o Estado é o produtor, destinatário e intérprete de suas normas- contribuía para isso. Porém, com o reconhecimento da jurisdição de tantos órgãos internacionais, o Brasil demonstrou para a comunidade internacional que não mais deseja ser ilusionista, o que nos fortalece e nos diferencia de outros países.

Para citar um exemplo claro de ilusionismo no Brasil, era possível um determinado Tribunal Superior brasileiro invocar as garantias processuais penais à luz da Convenção Americana de Direitos Humanos (art. $8^{\circ}$, art. 25) e sequer citar um precedente de interpretação da Corte Interamericana de Direitos Humanos, criando uma Convenção Americana de Direitos Humanos Paralela ou ainda uma verdadeira Convenção Americana de Direitos Humanos Brasileira.

Isso era tão absurdo quanto imaginarmos a interpretação e aplicação por anos a fio da Constituição brasileira sem menção a qualquer precedente do Supremo Tribunal Federal. Ao fim e ao cabo, teríamos uma Constituição Brasileira Alternativa, totalmente diferente daquela aplicada diuturnamente pelo nosso Supremo Tribunal Federal.

Por isso, sempre defendi que não é suficiente ratificar e incorporar tratados de Direitos Humanos ou ainda defender seu estatuto normativo especial (supralegal ou mesmo constitucional). É necessário aceitar - em sua integralidade - a consequência da

38 RAMOS, André Carvalho. Responsabilidade internacional do estado por violação de direitos humanos. Revista CEJ, Brasília, n. 29, p. 53-63, abr./jun. 2005. 
internacionalização dos Direitos Humanos, que vem a ser o acatamento da interpretação internacional sobre esses direitos. A internacionalização dos Direitos Humanos não pode ser restrita aos textos dos tratados: a interpretação deles não pode continuar a ser nacional.

Esse caminho nacionalista nega a universalidade dos Direitos Humanos e transforma os tratados e a Declaração Universal de Direitos Humanos em peças de retórica, pois permite que cada país interprete o que é tortura, intimidade, devido processo legal e outros comandos abertos dos textos de Direitos Humanos, gerando riscos de abuso e relativismo puro e simples.

No caso brasileiro, esse caminho nacionalista é, além disso, um beco sem saída, pois o Brasil já reconheceu a jurisdição da Corte Interamericana de Direitos Humanos, do Tribunal Internacional Penal (TPI), bem como se submeteu a diversos Comitês de Direitos Humanos estabelecidos em tratados celebrados sob os auspícios da Organização das Nações Unidas.

Caso paradigmático do beco sem saída da interpretação nacionalista dos tratados ocorreu recentemente, no chamado Caso da Guerrilha do Araguaia. Pela primeira vez, um tema (superação - ou não - da anistia a agentes da ditadura militar brasileira) foi analisado pelo Supremo Tribunal e pela Corte Interamericana de Direitos Humanos. ${ }^{39}$

No âmbito do STF, foi proposta, em outubro de 2008 pelo Conselho Federal da Ordem dos Advogados do Brasil (OAB), uma Arguição de Descumprimento de Preceito Fundamental (ADPF n. 153), pedindo que fosse interpretado o parágrafo único do art. $1^{\circ}$ da Lei 6.683 de $1979^{40}$ conforme a Constituição de 1988, de modo a declarar, à luz de seus preceitos fundamentais, que a anistia concedida pela citada lei aos crimes políticos ou conexos não se estende aos crimes comuns praticados pelos agentes da repressão (civis ou militares) contra opositores políticos, durante o regime militar.

Como fundamento, a OAB, tendo entre seus advogados o Professor Titular das Arcadas, Fábio Konder Comparato, invocou os preceitos fundamentais constitucionais da isonomia (art. $5^{\circ}$, caput), direito à verdade (art. $5^{\circ}$, XXXIII) e os princípios republicano, democrático (art. $1^{\circ}$, parágrafo único) e da dignidade da pessoa humana (art. $1^{\circ}$, III). Em síntese, a procedência da ação afastaria um dos principais argumentos ao longo dos anos

39 RAMOS, André de Carvalho. Crimes da ditadura militar: a ADPF 153 e a Corte Interamericana de Direitos Humanos. GOMES, Luiz Flávio; MAZZUOLI, Valério de Oliveira (org.). Crimes da Ditadura Militar. São Paulo: Revista dos Tribunais, 2011.

40 Lei n. 6.683, de 28 de agosto de 1979 . Art. $1^{\circ}$ É concedida anistia a todos quantos, no período compreendido entre 02 de setembro de 1961 e 15 de agosto de 1979, cometeram crimes políticos ou conexo com estes, crimes eleitorais, aos que tiveram seus direitos políticos suspensos e aos servidores da Administração Direta e Indireta, de fundações vinculadas ao poder público, aos Servidores dos Poderes Legislativo e Judiciário, aos Militares e aos dirigentes e representantes sindicais, punidos com fundamento em Atos Institucionais e Complementares. $\S 1^{\circ}$ - Consideram-se conexos, para efeito deste artigo, os crimes de qualquer natureza relacionados com crimes políticos ou praticados por motivação política. 
a favor da impunidade dos agentes da repressão durante o regime militar: a de que teriam sido anistiados. ${ }^{41}$

Por sua vez, em 26 de março de 2009, a Comissão Interamericana de Direitos Humanos (Comissão IDH) processou o Brasil perante a Corte Interamericana de Direitos Humanos (sediada em San José, guardiã da Convenção Americana de Direitos Humanos), invocando, ao seu favor (entre outros argumentos), a copiosa jurisprudência daquela Corte contrária às leis de anistia e favorável ao dever de investigação, persecução e punição penal dos violadores bárbaros de Direitos Humanos. Para a Comissão, o Brasil deve responder pela detenção arbitrária, tortura e desaparecimento forçado de 70 pessoas, entre membros do Partido Comunista do Brasil (PC do B) e camponeses da região, como resultado de operações do Exército brasileiro empreendidas entre 1972 e 1975 com o objetivo de erradicar a Guerrilha do Araguaia, no contexto da ditadura militar do Brasil (1964 - 1985). Ainda segundo a petição inicial da Comissão, o Estado deve ser responsabilizado internacionalmente por não ter realizado uma investigação penal com o objetivo de julgar e sancionar os responsáveis pelo desaparecimento forçado das 70 vítimas e pela execução extrajudicial da Senhora Maria Lucia Petit da Silva, cujos restos mortais foram encontrados e identificados em 14 de maio de 1996. Também a Comissão considerou que os recursos judiciais de natureza civil com vistas a obter informação sobre os fatos não foram efetivos para garantir aos familiares das vítimas o acesso à informação sobre a Guerrilha do Araguaia e as medidas legislativas e administrativas adotadas pelo Estado restringiram indevidamente o direito de acesso à informação dos familiares. Por fim, a impunidade dos responsáveis e a falta de acesso à justiça, à verdade e à informação, violaram o direito à integridade psíquica dos familiares dos desaparecidos e da pessoa executada.

Além do tema (lei da anistia) e do impacto sobre os familiares que até hoje esperam por justiça, a ADPF n. 153 impressiona por um fato inédito: pela primeira vez uma ação perante o Supremo Tribunal Federal com efeito vinculante e erga omnes (características da ADPF) foi processada simultaneamente a um processo internacional com objeto semelhante em curso perante a Corte Interamericana de Direitos Humanos.

A ADPF n. 153 foi julgada em 28 de abril de 2010, com a participação de apenas nove Ministros do STF, pois o Min. Joaquim Barbosa estava licenciado e ainda declarou-se suspeito o Min. Dias Toffoli. Inicialmente, foram rejeitadas as preliminares, vencido o Min. Marco Aurélio, que votou pela extinção da ação por falta de interesse de agir. No mérito, sete Ministros declararam improcedente a argüição (Ministros Eros Grau - Relator, Carmen Lúcia, Ellen Gracie, Marco Aurélio, Cezar Peluso, Celso de Mello

41 A ADPF não elimina, é claro, outros argumentos a favor dos agentes da repressão, em especial: ofensa ao princípio da legalidade estrita penal (por exemplo, crime de tortura não era tipificado na época) e ainda prescrição dos crimes (inclusive dos homicídios). 
e Gilmar Mendes) e dois votaram pela procedência parcial (Ministros Lewandowski, Professor das Arcadas, e Carlos Britto). Assim, para o STF, a lei da anistia alcança os agentes da ditadura militar, tornando impossível a persecução criminal pelas graves violações de Direitos Humanos ocorridas na época dos anos de chumbo.

Contudo, em 24 de novembro de 2010, meses após a decisão do STF, a Corte Interamericana de Direitos Humanos condenou o Brasil, exigindo que fosse feita completa investigação, persecução e punição criminal aos agentes da repressão política durante a ditadura militar, ${ }^{42}$ mandando o Brasil desconsiderar, então, a extensão da Lei da Anistia para tais indivíduos.

A defesa brasileira chegou até a informar a Corte de San José sobre a ADPF n. 153 e seu efeito vinculante e erga omnes, defendendo sem êxito o respeito à decisão do nosso STF. De fato, cabe à Corte Interamericana exigir o cumprimento da Convenção Americana de Direitos Humanos (na sua interpretação) do Estado brasileiro, o que atinge todos os seus órgãos, judiciais ou não.

Resta, agora, aos membros de todos os Poderes, responder a seguinte pergunta: é possível cumprir uma decisão de um órgão internacional de Direitos Humanos, como, por exemplo, a Corte Interamericana de Direitos Humanos (Corte IDH), após o Supremo Tribunal Federal ter decidido em sentido contrário o mesmo objeto da lide processada internacionalmente?

Antes de responder, parto da seguinte premissa: não há conflito insolúvel entre as decisões do STF e da Corte IDH, uma vez que ambos os tribunais têm a grave incumbência de proteger os Direitos Humanos. Para resolver esses conflitos aparentes, há dois instrumentos.

O primeiro deles é preventivo e consiste no apelo ao Diálogo das Cortes e à fertilização cruzada entre os tribunais. Com isso, antevejo, no futuro, o uso pelo STF das posições dos diversos órgãos internacionais de Direitos Humanos aos quais o Brasil já se submeteu.

Claro que não é possível obrigar os juízos nacionais ao Diálogo das Cortes, pois isso desnaturaria a independência funcional desses agentes políticos e o Estado Democrático de Direito.

Assim, no caso do diálogo inexistir ou ser insuficiente, adoto a teoria do duplo controle ou crivo de Direitos Humanos, que reconhece a atuação em separado do controle de constitucionalidade (STF e juízos nacionais) e do controle de convencionalidade (Corte de San José e outros órgãos de Direitos Humanos do plano internacional).

42 Corte Interamericana de Direitos Humanos, Caso Gomes Lund e outros vs. Brasil, Mérito, Sentença de 24 de novembro de 2010. Disponível em: <http://www.corteidh.or.cr/docs/casos/articulos/seriec_219_por. pdf>. Acesso em: 10 fev. 2011. 
Os Direitos Humanos, então, no Brasil possuem uma dupla garantia: o controle de constitucionalidade nacional e o controle de convencionalidade internacional. Qualquer ato ou norma deve ser aprovado pelos dois controles, para que sejam respeitados os direitos no Brasil.

Esse duplo controle parte da constatação de uma verdadeira separação de atuações, na qual inexistiria conflito real entre as decisões porque cada Tribunal age em esferas distintas e com fundamentos diversos.

Para explicar essa separação de atuações, cabe lembrar que a própria Constituição brasileira mencionou expressamente tanto o Supremo Tribunal Federal (art. 102, entre outros) quanto os tratados internacionais de Direitos Humanos (art. 5º, parágrafos segundo e terceiro) e um tribunal internacional de Direitos Humanos (art. $7^{\circ}$ da ADCT).

Para compatibilizar esses dispositivos, é necessário separar as respectivas áreas de atuação, conforme o marco teórico que defendi, em 2002, em palestra dada no Seminário Constituição em Crise ou Constituição Desafiada?, realizado em Belo Horizonte. ${ }^{43}$

De um lado, o STF, que é o guardião da Constituição e exerce o controle de constitucionalidade. Por exemplo, na ADPF n. 153 (controle abstrato de constitucionalidade), a maioria dos votos decidiu que a anistia aos agentes da ditadura militar é a interpretação adequada da Lei da Anistia e esse formato amplo de anistia é que foi recepcionado pela nova ordem constitucional.

De outro lado, a Corte de San José é guardiã da Convenção Americana de Direitos Humanos e dos tratados de Direitos Humanos que possam ser conexos. Exerce, então, o controle de convencionalidade. Para a Corte Interamericana, a Lei da Anistia não é passível de ser invocada pelos agentes da ditadura. Mais: sequer as alegações de prescrição, bis in idem e irretroatividade da lei penal gravior merecem acolhida.

Com base nessa separação, vê-se que é possível dirimir o conflito aparente entre uma decisão do STF e da Corte de San José. Assim, ao mesmo tempo em que se respeita o crivo de constitucionalidade do STF, deve ser incorporado o crivo de convencionalidade da Corte Interamericana de Direitos Humanos. Todo ato interno (não importa a natureza ou origem) deve obediência aos dois crivos. Caso não supere um deles (por violar Direitos Humanos), deve o Estado envidar todos os esforços para cessar a conduta ilícita e reparar os danos causados.

No caso da ADPF n. 153, houve o controle de constitucionalidade. No caso Gomes Lund, houve o controle de convencionalidade. A anistia aos agentes da ditadura,

43 Posteriormente publicada em coletânea. Ver RAMOS, André de Carvalho. A expansão do direito internacional e a constituição brasileira: novos desafios. In: SAMPAIO, José Adércio Leite. (Org.). Crise e desafios da constituição. Belo Horizonte: Del Rey, 2004. p. 291-320. 
para subsistir, deveria ter sobrevivido intacta aos dois controles, mas só passou (com votos contrários, diga-se) por um, o controle de constitucionalidade. Foi destroçada no controle de convencionalidade. Por sua vez, as teses defensivas de prescrição, legalidade penal estrita, etc., também deveriam ter obtido a anuência dos dois controles. Como tais teses defensivas não convenceram o controle de convencionalidade e dada a aceitação constitucional da internacionalização dos Direitos Humanos, não podem ser aplicadas internamente.

Não cabe, então, alegar coisa julgada ou efeito vinculante para obstar inquéritos policiais ou ação penal que estejam a aplicar a sentença interamericana, pois não houve rescisão ou declaração de nulidade da decisão da ADPF n. 153, que continua a produzir efeitos no que tange aos seus fundamentos de direito interno. Só que as autoridades envolvidas devem cumprir agora a sentença internacional, com base no art. $7^{\circ}$ da ADCT, bem como os demais artigos que tratam de tratados internacionais de Direitos Humanos.

Essa teoria do duplo controle permite a convivência entre as ordens normativas justapostas na defesa de Direitos Humanos.

Não se desafia o STF, mas sim ficam esclarecidos os campos de atuação: para a Alta Corte nacional há a palavra final sobre o ordenamento nacional; para a Corte Interamericana de Direitos Humanos resta a palavra final sobre a Convenção Americana de Direitos Humanos, costume internacional e tratados conexos, que incidem também sobre o Brasil.

Podemos usar a teoria do duplo controle não somente para os casos de Direitos Humanos, mas para todos os casos de aplicação de normas internacionais sujeitas a órgãos internacionais de interpretação, como, por exemplo, as normas da Organização Mundial do Comércio (submetidas ao sistema de solução de controvérsias daquela organização), as normas mercosulinas (submetidas às arbitragens ad hoc e ao Tribunal Permanente de Revisão), etc.

Assim, por exemplo, uma conduta de discriminação a importadores de automóveis (aumentando o Imposto sobre Produtos Industrializados) deve passar pela teoria do duplo controle: ser considerada constitucional pelo STF e ainda conforme aos tratados da $O M C$, de acordo com o sistema da OMC de solução de controvérsias. Se passar por um só desses crivos, não poderá ser aplicada internamente.

A partir da teoria do duplo controle, agora deveremos nos acostumar a exigir que todo ato interno se conforme não só ao teor da jurisprudência do STF, mas também ao teor da jurisprudência internacional (cujo conteúdo deve ser estudado inclusive nas Faculdades de Direito). 
Conclusão

O maior entusiasmo dos constitucionalistas sobre o tema da pluralidade das ordens jurídicas ${ }^{44}$ é explicado pela novidade: acostumados à supremacia da Constituição, a invasão internacionalista surpreendeu e mereceu inúmeros estudos, em especial na Europa no pós-Tratado de Maastricht (1992) que chegou ao ponto de estabelecer o cronograma de implantação de uma moeda única (o euro).

Para os internacionalistas, essa internacionalização da vida social só é consequência natural do robustecimento da própria disciplina. O fato de uma norma internacional regular facetas cruciais da vida interna (Direitos Humanos, liberdade de circulação dos fatores de produção capitalista e moeda comum, políticas públicas diversas, criminalização de condutas, etc.) não cria impacto maior ou suscita espanto. Também não chega a estarrecer a necessidade de, eventualmente, um Estado ter que alterar normas constitucionais originárias para fazer valer uma decisão de um órgão internacional.

Tudo seria fruto natural da própria existência do Direito Internacional.

Em que pese ser compreensível essa visão blasé, a pluralidade das ordens jurídicas interessa em muito ao Direito Internacional.

Como visto acima, há tanto harmonia quanto dissonância no encontro das normas internacionais e nacionais. A busca de parâmetros para estimular a harmonia (vide acima os parâmetros do diálogo das Cortes) e mecanismo para contornar o dissenso (vide a teoria do duplo controle) permite antever um relacionamento mais convergente entre as ordens jurídicas plurais.

Sem contar que, se os fenômenos associados à dissonância aumentarem, há sempre o risco da solução de ruptura, que vem a ser a denúncia de tratados e o isolamento do Estado. Claro que esse risco é cada vez menor em países com ambições de protagonismo no plano internacional, como o Brasil, mas já ocorreram casos no passado. No que tange à Corte Interamericana de Direitos Humanos (cuja decisão no Caso da Guerrilha do Araguaia usamos como exemplo), há o fantasma de Trinidad e Tobago: insatisfeita com as decisões da Corte IDH, Trinidad simplesmente denunciou a Convenção Americana de Direitos Humanos, estando até hoje dela afastada.

Evitar a ruptura e estimular a convergência em prol da humanidade é uma tarefa que se impõe aos estudiosos da pluralidade das ordens jurídicas.

São Paulo, outubro de 2011.

44 Esse entusiasmo constitucionalista é comprovado pela criação de inúmeras denominações razoavelmente equivalentes (vide acima) sobre a temática da pluralidade das ordens jurídicas. 


\section{Referências}

ARAGÓN REYES, Manuel. La Constitución como paradigma. In: CARBONELL SÁNCHEZ, Miguel. Teoría del neoconstitucionalismo: ensayos escogidos. Madrid: Trotta, 2007. p. 29-40.

CANOTILHO, José Joaquim Gomes. Brancosos e Interconstitucionalidade. Itinerários dos Discursos sobre a Historicidade Constitucional. Coimbra: Almedina, 2008.

RAMOS, André de Carvalho. A expansão do direito internacional e a constituição brasileira: novos desafios. In: SAMPAIO, José Adércio Leite. (Org.). Crise e Desafios da Constituição. Belo Horizonte: Del Rey, 2004. p. 291-320.

. Crimes da ditadura militar: a ADPF 153 e a Corte Interamericana de Direitos Humanos. GOMES, Luiz Flávio; MAZZUOLI, Valério de Oliveira (Org.). Crimes da ditadura militar. São Paulo: Revista dos Tribunais, 2011.

. O diálogo das cortes: O supremo tribunal federal e a corte interamericana de direitos humanos. In: AMARAL JUNIOR, Alberto do; JUBILUT, Liliana Lyra (Org.). O STF e o direito internacional dos direitos humanos. São Paulo: Quartier Latin, 2009. p. 805-850.

. Responsabilidade internacional do estado por violação de direitos humanos. Revista CEJ, Brasília, v. 29, p. 53-63, 2005.

. Rule of law e a judicialização do Direito Internacional: da mutação convencional às guerras judiciais. In: BEDIN, Gilmar Antonio. (Org.). Estado de direito, jurisdição universal e terrorismo. Ijui: Unijui, 2009. v. 1, p. 85-122.

Direitos humanos na integração econômica. Rio de Janeiro: Renovar, 2008.

. Processo internacional de direitos humanos. 2. ed. São Paulo: Saraiva, 2012.

Teoria geral dos direitos humanos na ordem internacional. 2. ed. São Paulo: Saraiva,

2012.

DELMAS-MARTY, Mireille. Le pluralisme ordonné. Paris: Seuil, 2004.

DUPUY, Pierre-Marie. The danger of fragmentation or unification of the international legal system and the International Court of Justice. New York University Journal of International Law and Politics, p.791-807, 1999.

JACOBS, Francis G. Judicial Dialogues and Cross-Fertilization of Legal Systems: the European Court of Justice. Texas International Law Journal, p. 547-566, 2003.

KUMM, Mattias. Who is the final arbiter of constitucionality in Europe? Three conceptions of the relationship between the German Federal Constitucional Court and the European Court of Justice. Common Market Law Review, p. 351-386, 1999.

NEUMAN, Gerald L. Human Rights and Constitutional Rights: Harmony and Dissonance. Stanford Law Review, p. 1863-1900, 2003. 
NEVES, Marcelo. Transconstitucionalismo. São Paulo: Martins Fontes, 2009.

PERNICE, Ingolf. Multilevel constitutionalism and the Treaty of Amsterdam: European constitutionmaking revisited in 36. Common Market Law Review, p.703-750, 1999.

PERNICE, Ingolf. The Treaty of Lisbon: Multilevel Constitutionalism in Action. The Columbia Journal of European Law, v. 15, n. 3, p. 350-407, Summer, 2009.

ROMANO, Cesare. The proliferation of international judicial bodies: the pieces of the puzzel. New York University Journal of International Law and Politics, New York, p. 710-751, 1999.

ROTHENBURG, Walter Claudius. Direito constitucional. São Paulo: Verbatim, 2010.

SARMENTO, Daniel. O neoconstitucionalismo no Brasil: riscos e possibilidades. In: LEITE, George Salomão; SARLET, Ingo Wolfgang. (Org.). Direitos fundamentais e estado constitucional: Estudos em Homenagem a J.J. Gomes Canotilho. São Paulo: Editora Revista dos Tribunais; Coimbra: Coimbra Editora, 2009. p. 9-49.

SHANY, Yuval. The competing jurisdictions of International Courts and Tribunals. Oxford: Oxford University Press, 2003. p. 109.

TAVARES, André Ramos. Modelos de uso da jurisprudência constitucional estrangeira pela justiça constitucional. Revista Brasileira de Estudos Constitucionais, Belo Horizonte, a. 3, n.12, p. 17-55, 2009.

WALKER, Neil. The Idea of Constitutional Pluralism. in 65 The Modern Law Review, p. 317 e ss, 2002. 